\title{
Assessment of the Hydrocarbon Degrading Abilities of Three Bioaugmentation Agents for the Bioremediation of Crude Oil Tank Bottom Sludge Contaminated Libyan Soil
}

\author{
Abdulatif A. Mansur ${ }^{1,2, *}$, Eric M. Adetutu ${ }^{1}$, Tanvi Makadia1, Paul D. Morrison' ${ }^{1}$, Andrew S. Ball ${ }^{1}$ \\ ${ }^{1}$ School of Applied Sciences, Royal Melbourne Institute of Technology, Melbourne 3083, Australia \\ ${ }^{2}$ Environmental and Natural Resources Engineering, Faculty of Engineering, Azawia University, Libya \\ *Corresponding author: S3370890@student.rmit.edu.au
}

Received January 08, 2015; Revised January 25, 2015; Accepted February 02, 2015

\begin{abstract}
Bioremediation is a widely used environmental friendly treatment method for petrogenic hydrocarbon contaminated soils but its application to the treatment of crude oil tank bottom sludge (COTBS) contaminated soil is limited especially in Mediterranean countries such as Libya. Therefore in this study, the hydrocarbon degrading abilities of three bioaugmentation agents Pseudomonas sp (4M12), Pseudomonas xanthomarina (4M14) and Arthrobacter nitroguajacolicus (1B16A) (isolated from COTBS polluted soils) applied as part of a biostimulation-bioaugmentation (BS/BA) strategy were assessed in COTBS contaminated Libyan soils. Biostimulated (BS) and natural attenuation (NA) microcosms were also set up for comparative purposes. Gas chromatograph mass spectrometer (GC- MS) analysis revealed a total soil petroleum hydrocarbon (TPH) and polycyclic aromatic hydrocarbon (PAHs) content of $30,703 \mathrm{mg} \mathrm{kg}$ and $13,816 \mathrm{mg} \mathrm{kg}^{-1}$ respectively. Two carcinogenic fractions (naphthalene and benzenamine, 4, 4`methylenbis [2-methyl-]) and 4 mutagenic fractions (pyrene, phenanthrene, fluorene and anthracene) were detected. Substantial PAH degradation occurred in 4M14 and 4M12 samples within 15 days in contrast to up to 23 days in 1B16A, NA. However, substantial reduction in TPH (> 97\%) was only observed in 4M12 and 4M14 inoculated microcosms within 15 days compared to 25-30 days in 1B16A inoculated, BS and NA microcosms. 4M14 inoculated microcosms were most efficient at complete removal (D100) of all carcinogenic and mutagenic fractions; 4M14 (9-10 days), 4M12 (9-15 days), 1B16A (15-23 days), BS (18-21 days) and NA (18-22 days). Pseudomonas xanthomarina was therefore shown as the best candidate for use in a BS/BA approach for treating COTBS contaminated Libyan soils. This study shows the importance of pre-screening bioaugmentation agents for the removal of carcinogenic and mutagenic fractions prior to use; in order to carry out safe, efficient and sustainable COTBS bioremediation in Libya.
\end{abstract}

Keywords: Crude oil tank bottom sludge (COTBS), slurry phase bioremediation, biostimulation, bioaugmentation, gas chromatograph mass spectrometer (GC-MS)

Cite This Article: Abdulatif A. Mansur, Eric M. Adetutu, Tanvi Makadia, Paul D. Morrison, and Andrew S. Ball, "Assessment of the Hydrocarbon Degrading Abilities of Three Bioaugmentation Agents for the Bioremediation of Crude Oil Tank Bottom Sludge Contaminated Libyan Soil." International Journal of Environmental Bioremediation \& Biodegradation, vol. 3, no. 1 (2015): 1-9. doi: 10.12691/ijebb-3-1-1.

\section{Introduction}

Global oil production in 2013 was estimated at 75.6 M bbl.day ${ }^{-1}[1]$. At oil refineries, crude oil is stored in large storage tanks pending processing. During this time, crude oil tank bottom sludge (COTBS) is generated as a result of the settlement of suspended solids; millions of tonnes of sludge (COTBS) are generated annually worldwide [2,3]. Apart from labour costs and waste management issues associated with COTBS removal, its presence in holding tanks reduces the oil storing capacity of tanks with the increasing possibility of tank corrosion. Periodical removal of sludge therefore becomes necessary [4].

COTBS contains a mixture of hydrocarbon fractions ranging from alkanes to polycyclic aromatic hydrocarbons (PAHs), [5] and heavy molecular weight hydrocarbons (HMWHCs) above $\mathrm{C}_{40}$ [6]. Some fractions such as PAHs (a significant component of COTBS [7]) have carcinogenic and mutagenic characteristics to living organisms [8]. Detoxification of COTBS contaminated soil is therefore essential prior to disposal or re-use

Biological treatment or bioremediation is a wellestablished and widely used treatment method of hydrocarbon and COTBS contaminated soils [9,10,11,12]. This is because of its efficient, cost effective and 
environmental friendly nature compared to chemical and physical treatment approaches. The mechanisms and methods involved in the bioremediation of different hydrocarbon polluted environments are well reviewed $[13,14]$. One commonly used bioremediation method involves the use of a combination of biostimulation (nutrient addition) and bioaugmentation (addition of hydrocarbon degrading microorganisms) strategies. This approach has been successfully used to treat hydrocarboncontaminated soils in solid and slurry phases, with slurry phase bioremediation providing faster and greater hydrocarbon degradation $[10,15,16]$.

The focus of most bioremediation studies is on how effective a chosen treatment strategy is in reducing contaminant concentration to legislated disposal thresholds within a stipulated time frame and at minimal costs. Although, the efficiency of this process is affected by a variety of well-studied soil and environmental factors such as temperature, moisture content, nutrients, pollutant type and bioavailability, the available microbial capacity is crucial to successful bioremediation [17-21]. However, there are limited reports on the comparative hydrocarbon removal efficiencies of hydrocarbonoclastic isolates in most studies involving the use of a biostimulationbioaugmentation strategy.

Selection of bioaugmentation agents is based on (i) endpoint hydrocarbon degradation values, with microorganisms with lower endpoint values being selected and (ii) the ability of the selected strains for fast multiplication and growth rate within the treatment conditions [17]. While hydrocarbonoclastic microorganisms are able to degrade hydrocarbons, the types of hydrocarbon degraded and rate of removal may vary [22]. There is limited information available on when a particular fraction is removed by a microbial isolate and whether this knowledge could be important in the selection of organisms to be used for bioaugmentation. For example, given that COTBS contains carcinogenic and mutagenic fractions such as $\mathrm{PAH}$ [23], selecting bioaugmentation agents that are able to remove these fractions faster would be beneficial to the bioremediation process in terms of process efficiency and reduction in health risks to practitioners.

In most Mediterranean countries such as Libya, bioremediation is poorly practised despite the occurrence of significant amount of soil pollution by COTBS and petrogenic hydrocarbons. This study is part of a larger study designed to isolate, screen and utilize hydrocarbonoclastic isolates from COTBS for large scale ex situ remediation of COTBS contaminated soils. Successful bioremediation outcome is expected to accelerate the acceptance and utilization of this technology for the treatment of contaminated environments in Mediterranean countries. Earlier work on a Libyan soil contaminated with COTBS had led to the isolation of 49 hydrocarbonoclastic bacterial isolates of which seven isolates were selected for further evaluations based on their high hydrocarbon degrading properties [24]. Out of these seven isolates, 3 were selected as the best COTBS degraders for use in this study.

This study therefore aims to evaluate and compare the efficiencies of these isolates in degrading the Hamada crude oil contaminants in soil samples in order to select the best isolates for use in a bioaugmentation- biostimulation bioremediation strategy. Using chemical assays, this study will determine (i) the carcinogenic and mutagenic fractions that were degraded in microcosms inoculated with selected isolates (ii) when these fractions were degraded and (iii) the endpoint values for TPH and $\mathrm{PAH}$ in microcosms set-up with selected isolates in laboratory based slurry-phase experiments. Changes in the microbial community are also assessed using a PCRDGGE approach.

\section{Materials and Methods}

\subsection{Soil Samples}

COTBS contaminated soil samples were collected from Azzawiya oil refinery in Libya. Samples (5 kg) were collected from the top $0-30 \mathrm{~cm}$ of contaminated soil stockpiles, sieved and stored in zip lock plastic bags. The samples were transported to RMIT University in Melbourne, Australia, coded and stored in a Quarantine facility.

\subsection{Physico-chemical Characterizations}

The soil texture, moisture content and $\mathrm{pH}$ of the soil samples were determined using standard methods [25]. The water-holding capacity was determined as described by [26]. The concentrations of $\mathrm{C}$ and $\mathrm{N}$ were measured by a model LECO TruMac CNS analyser following the manufacturer's instructions. This involved sample combustion at $1250^{\circ} \mathrm{C}$ with infrared detection being used to detect the total carbon and a thermal conductivity cell for total nitrogen detection [27]. Phosphorus concentration was analysed using a Perkin Elmer Optima 7000 DV ICPOSE (SESL lab Thornleigh, NSW, Australia) as per US EPA methods (3050B) after acid digestion of the contaminated soils at $60^{\circ} \mathrm{C}$. Metals (potassium and Calcium) concentrations were analysed using flame atomic absorption spectrophotometer (Varian Model Spectra AA 220) as per the manufacturer's protocol. Briefly, soil samples were digested in test tubes at $60^{\circ} \mathrm{C}$ in a hot block with $5 \mathrm{ml} \mathrm{HCl}$ (70-75\% concentration) and 5 ml hydrogen peroxide (30\% concentration). The samples were then kept at $120^{\circ} \mathrm{C}$ for 150 min before being analysed as per the manufacturer`s suggested conditions [28].

\subsection{Preparing Bacterial Isolates for Microcosms}

Three bacterial isolates previously isolated and identified in a previous study [24] (Table 1) were selected for use based on their hydrocarbon degrading properties. These isolates (designated as 4M14, 4M12 and IB16A) were obtained from stocks of pure cultures maintained at $80^{\circ} \mathrm{C}$ in $50 \%$ glycerol and streaked individually on nutrient agar plates (Acumedia, Lansing, Michigan 48912) (26 g/ 1 adjusted to $\mathrm{pH}$ 7.4). The streaked plates were incubated at $30^{\circ} \mathrm{C}$ for up to $3 \mathrm{~d}$ after which they were inoculated into nutrient broth (30 ml; Acumedia, Lansing, Michigan 48912). Nutrient broth incubation was at $30^{\circ} \mathrm{C}$ for $48 \mathrm{~h}$ at $120 \mathrm{rev}$ min-1. Cultures of $\mathrm{OD}_{600}$ 0.689-1.056 were harvested by centrifugation at $4^{\circ} \mathrm{C}$ at $16,000 \times \mathrm{g}$ for 2 min and washed twice with sterile distilled water [23]. The pellets were then re-suspended individually in 
distilled water $(5 \mathrm{ml})$ for the bioremediation experiments.

Triplicate samples were used for all experimental work.

Table 1. Carcinogenic and mutagenic fractions detected in COTBS contaminated soil

\begin{tabular}{|c|c|c|}
\hline Hydrocarbon fraction & Effect on living organisms & Reference \\
\hline Naphthalene*a & Possibly Carcinogenic to humans & $\begin{array}{c}\text { (Lerda, 2010) (IARS, EPA and EU } \\
\text { classifications) }\end{array}$ \\
\hline $\begin{array}{c}\text { Benzenamine,4,4methy lenbis[2- } \\
\text { methyl-]*a }\end{array}$ & Carcinogenic in rats & (Gini et al., 1999, Haseman et al., 1987) \\
\hline Pyrene*b & Mutagenic but in other forms such as Dibenzo[a]Pyrene & $\begin{array}{c}\text { (Oostingh et al., 2008, Lerda, 2010, } \\
\text { Perelo, 2010) }\end{array}$ \\
\hline Phenanthrene*b & Mutagenic to humans (could destroy the immune system & (Oostingh et al., 2008, Perelo, 2010) \\
\hline Flourene*b & $\begin{array}{c}\text { Mutagenic to humans (harmful effects of fluoride intoxication on the } \\
\text { living tissues) }\end{array}$ & $\begin{array}{c}\text { (Oostingh et al., 2008, Perelo, 2010, } \\
\text { Nabavi et al., 2012) }\end{array}$ \\
\hline Anthracene*b & $\begin{array}{c}\text { Mutagenic but in forms of 7,12- Dimethylbenz [a] anthracene } \\
\text { (DMBA) is carcinogenic to humans }\end{array}$ & (Yardım et al., 2010, Perelo, 2010) \\
\hline
\end{tabular}

\subsection{Preparation of Slurries and Strain Inoculation}

Slurry phase experiments for assessing the biodegradation of COTBS in contaminated soil were carried out in $250 \mathrm{ml}$ flasks. The slurries were prepared in triplicate by adding $30 \mathrm{~g}$ of COTBS contaminated soil to $150 \mathrm{ml}$ of autoclaved deionized water to obtain a 1: 5 soil: solution ratio [29]. During slurry preparation, nutrients $\left(\mathrm{NH}_{4}\right)_{2} \mathrm{SO}_{4}(0.43 \mathrm{~g}), \mathrm{K}_{2} \mathrm{HPO}_{4}(0.05 \mathrm{~g})$ and $\mathrm{KH} 2 \mathrm{PO} 4(0.04 \mathrm{~g})$ were added to achieve a $\mathrm{C}: \mathrm{N}: \mathrm{P}$ molar ratio of around 100:10:1 [29] to enhance bacterial growth. An aliquot (5 $\mathrm{ml}$ ) of each individual bacterial isolate was inoculated with an initial inoculum size of $1 \times 104$ cell ml $^{-1}[30,31]$. Inoculated flasks were maintained on shaker incubators [32] with continuous rotation of $150 \mathrm{rpm}$ for $35 \mathrm{~d}$ at $30^{\circ} \mathrm{C}$. To prevent photo-degradation, experiments were carried out in the dark [32]. Three types of microcosms were incubated; (i) COTBS contaminated soil plus water plus nutrients and individual isolates (BS/BA) (ii) COTBS contaminated soil plus water plus nutrients (BS) (iii) COTBS contaminated soil plus only water (NA). Sampling was carried every 5 days from each flask in order to assess the changes in total petroleum hydrocarbon (TPH) concentration and soil bacterial community.

\subsection{Hydrocarbon Extraction}

Oil was extracted in triplicate samples by solvent extraction (dichloromethane (DCM)) and air-dried using a previously described protocol [33] with some modifications. Briefly, triplicate slurry samples were air dried overnight at room temperature [31]. Dried samples were placed in a Teflon coated centrifuge tubes $(25 \mathrm{ml})$ and (DCM) (3 ml) was added (1:3 soil: solvent ratio). The oil in this mixture was extracted by agitation (130 rev min ${ }^{1}$ ) for $20 \mathrm{~min}$, followed by centrifugation at $5000 \mathrm{rev} \mathrm{\textrm {min } ^ { - 1 }}$ for $5 \mathrm{~min}$. The supernatants were removed into glass bottles $(15 \mathrm{ml})$ and concentrated by solvent evaporation overnight at room temperature [32,33]. The extracted oils were concentrated to $1 \mathrm{ml}$ in DCM [34] and placed in chromatographic vial $(2 \mathrm{ml}$ ) (Adel Lab Scientific, The Barton, SA, Australia) for further analysis.

\subsection{Determination of Hydrocarbon Concentration}

For the analysis of Total Petroleum Hydrocarbons including aromatic and aliphatic compounds concentrations, a combined paraffins, isoparaffins, aromatic, naphthalenes and oleffins (PIANO) PIANO-5Piano (DHA) standard combined set (2 ml ampule) (Spectrum Quality Standards, Ltd. Sugarland, TX, USA) was used. The hydrocarbon content of, the extracted oil was analysed as described in ASTM D5134 using gas chromatograph mass spectrometer (GC-MS) equipped with an autosampler (Agilent 6890 GC and Leco Pegasus III TOF-MS). Samples were injected and separated on a capillary column Agilent DB-5MS (60 m by $0.25 \mathrm{~mm}$ with $0.25 \mu \mathrm{m}$ film thickness). The injection temperature and volume was $225^{\circ} \mathrm{C}$ and $0.2 \mu \mathrm{l}$ respectively. Helium (1.8 ml min-1) was used as a carrier gas at a constant flow rate. The concentration of each hydrocarbon fraction was analyzed and the total peak area of each fraction was compared to the peak area of each fraction in the PIANO standard curve [31].

\subsection{DNA Extraction and PCR}

DNA extraction was carried out in triplicate slurry samples from days $0,5,10,15,20,25,30$ and 35 using a MO BIO Power Soil DNA isolation kit (MO BIO Laboratories, Inc, USA). One $\mathrm{ml}$ from each slurry sample was added to the PowerBead tubes and gently vortexed to mix. Solution C1 (60 $\mu \mathrm{l})$ was added and the tube inverted several times. Tubes were centrifuged at $10,000 \times \mathrm{g}$ for 30 $\mathrm{s}$ at room temperature after which the supernatants were transferred into clean collection tubes $(2 \mathrm{ml})$. Further processing was carried out as per the manufacturer's protocol. DNA was also extracted from the bacteria isolates as described in [35]

The polymerase chain reactions (PCR) of DNA extracts from slurry samples and isolates were conducted using a $50 \mu \mathrm{l}$ PCR master mix. The reactions were prepared using $2 \mu \mathrm{l}$ bacterial primers $341 \mathrm{FGC}(10 \mu \mathrm{M})$ and $518 \mathrm{R}(10 \mu \mathrm{M})$ [36,37], $3 \mu \mathrm{l} \mathrm{MgCl} 2(25 \mathrm{mM}), 1 \mu \mathrm{l}$ dNTP mixture (10 $\mathrm{mM}), 10 \mu \mathrm{l}$ of GoTaq flexi buffer (5x), $0.25 \mu \mathrm{l}$ of Tap polymerase enzyme $(5 \mathrm{U} / \mu \mathrm{l})$ and $29.75 \mu \mathrm{l}$ of sterile nuclease-free water per reaction. DNA extract $(2 \mu \mathrm{l})$ was added to $48 \mu \mathrm{l}$ of master mix. The thermocycling conditions were; an initial denaturing step at $95^{\circ} \mathrm{C}$ for 5 min, then $92^{\circ} \mathrm{C}$ for $30 \mathrm{~s}, 55^{\circ} \mathrm{C}$ for $30 \mathrm{~s}$ and $72^{\circ} \mathrm{C}$ for $1 \mathrm{~min}$ (25 cycles) and a final extension step at $72^{\circ} \mathrm{C}$ for $10 \mathrm{~min}$.

\subsection{Denaturing Gradient Gel Electrophoresis (DGGE) Analysis}

DGGE was performed on PCR amplicons using Universal Mutation Detection System D-code apparatus (Bio-Rad, CA, USA) as per the manufacturer protocol. The PCR products were loaded onto $9 \%(\mathrm{w} / \mathrm{v})$ polyacrylamide gel with a denaturing gradient of $45 \%$ to 
$65 \%$ and ran for $18 \mathrm{~h}$ at $60^{\circ} \mathrm{C}$ and $60 \mathrm{~V}$. PCR amplicons of the three isolates were loaded individually on single lanes and also mixed together and loaded as DGGE ladders. The DGGE gel was silver stained [38]. Briefly, DGGE gel was then incubated for $2 \mathrm{~h}$ in $200 \mathrm{ml}$ of fixing solution (40\% ethanol (100\%), $10 \%$ acetic acid, v/v) before being incubated in $200 \mathrm{ml}$ of silver nitrate solution $(0.2 \mathrm{~g}$ silver

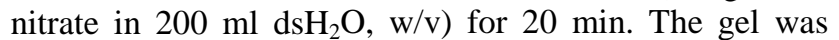
then held for 10-30 min in $200 \mathrm{ml}$ of developing solution (0.02 g sodium borohydride, $0.8 \mathrm{ml}$ formaldehyde, $3 \mathrm{~g}$

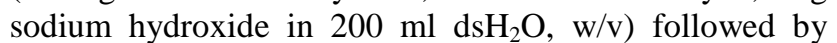
incubation in $200 \mathrm{ml}$ of fixing solution (10\% ethanol, 5\% acetic acid, v/v) for $10 \mathrm{~min}$. Finally, the gel was soaked in $200 \mathrm{ml}$ preservative solution ( $125 \mathrm{ml}$ of absolute ethanol, $50 \mathrm{ml}$ glycerol in $325 \mathrm{ml}$ of $\mathrm{dsH}_{2} \mathrm{O}, \mathrm{v} / \mathrm{v}$ ) for $10 \mathrm{~min}$. DGGE gels were scanned with an EPSON Expression 1600 V.2.65 E software [39] and digital images saved as tiff files.

\subsection{Statistical Analysis}

Digitized DGGE image was analysed TL120 software with the similarity relationship between the different communities analysed by the use of Unweighted Paired Group with Arithmetic Means (UPGMA). Statistical analyses were carried out using SPSS 20 using $\mathrm{T}$ Tests Significance was taken at $(\mathrm{P} \leq 0.05)$.

\section{Results and Discussion}

\subsection{Physico-chemical Analysis}

The contaminated soil used in this study was sandy loam in nature with a $\mathrm{pH}$ value of 6.8 (Table 2). TPH and PAH concentrations in this contaminated soil were 30,703 mg kg-1 and 13,816 mg kg-1 respectively. The results of heavy metal and nutrient assays are presented in Table 2.
GC-MS based analysis resulted in up to 150 different hydrocarbon fractions being detected which were grouped either as aromatic compounds (45\%) or aliphatic compounds (35.9\%) with some of these fractions (19.1\%) being unidentifiable. Out of these fractions, two carcinogens (benzenamine, 4, 4`methylenbis [2-methyl-] and naphthalene) and four mutagens (pyrene, phenanthrene, fluorene and anthracene) were identified (Table 2). The detection of carcinogenic and mutagenic fractions in COTBS is further evidence of their toxicity and need for proper detoxification of COTBS contaminated soils prior to discharge or re-use. Other studies have identified carcinogenic and mutagenic fractions such as fluoranthene, pyrene, benzo(a)anthracene and chrysene in COTBS [40].

Table 2. Physiochemical characteristics of Libyan COTBS contaminated soil

\begin{tabular}{|c|c|}
\hline Characteristic & Value \\
\hline $\mathrm{pH}$ & $6.8 \pm 0.3$ \\
\hline Moisture content (\%) & $7.02 \pm 0.2$ \\
\hline Soil texture & Sandy loam \\
\hline TPH (mg/kg) & $30703 \pm 101$ \\
\hline PAHs (mg/kg) & $13816 \pm 88$ \\
\hline $\mathrm{K}(\mathrm{mg} / \mathrm{kg})$ & $0.26 \pm 0.02$ \\
\hline $\mathrm{Ca} \mathrm{(mg/kg)}$ & $4.45 \pm 0.04$ \\
\hline Total N $(\%$ in 100 g) & $0.035 \pm 0.0$ \\
\hline Total P (mg/kg) & $167 \pm 0.0$ \\
\hline TOC (\% in 100 g) & $10.39 \pm 0.3$ \\
\hline
\end{tabular}

\subsection{Hydrocarbonoclastic Bacteria}

The identities of the three hydrocarbonoclastic bacteria had been determined in earlier studies [24]. The isolates were selected depending on the highest hydrocarbon degradation potential. Sequence analyses putatively identified 4M14 as Pseudomonas xanthomarina, 4M12 as Pseudomonas sp and IB16A as Arthrobacter nitroguajacolicus. The source, phyla, $\%$ similarity and accession numbers of these isolates are presented in Table 3.

Table 3. The identities of hydrocarbonoclastic isolates used in this study

\begin{tabular}{|c|c|c|c|c|c|}
\hline Isolate & Origin & Phylum & Identification & Accession no \\
\hline 4M14 & Treated soil & Gammaproteobacteria & Pseudomonas xanthomarina & HG & H608728.1 \\
\hline 4M12 & COTBS & Gammaproteobacteria & Pseudomonas sp & 96 \\
\hline 1B16A & Treated soil & Actinobacteria & Arthrobacter nitroguajacolicus & J662885.1 & JX483740.1 \\
\hline
\end{tabular}

\subsection{Hydrocarbon Degradation (TPH and PAH)}

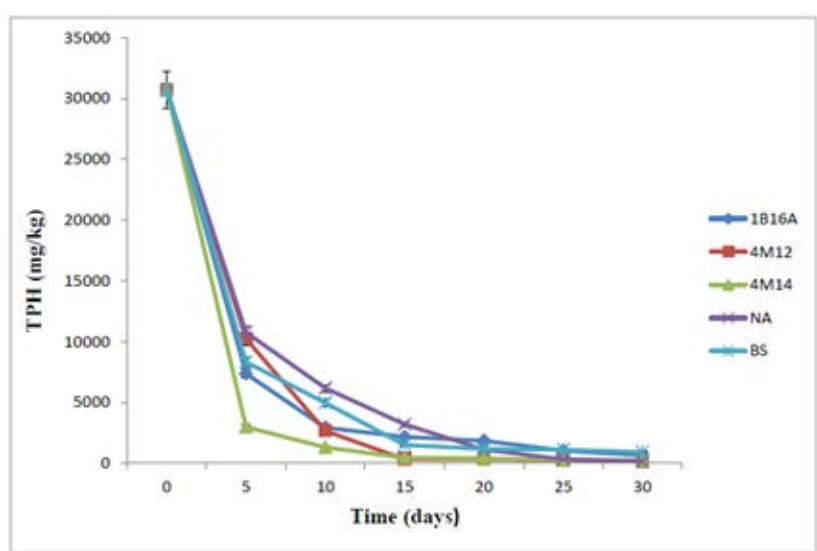

Figure 1. Reduction of TPH concentration by 3 individual bacterial isolates and NA and BS over $30 \mathrm{~d}$. Diamond (4M12), box (1B16A), triangle (4M14), plus (BS) and multiplication sign (NA)

Note: The values of the standard errors are very low. Therefore the error bars are short and some of them are invisible.
Analysis of the contaminant concentration throughout the experimental period showed that after $30 \mathrm{~d}$, the TPH concentration in the slurry phase (BS/BA and BS) naturally attenuated microcosms had decreased significantly (Figure 1) $(\mathrm{P}<0.05)$. However, highest TPH reduction occurred within the first 15 days in microcosms with hydrocarbonoclastic isolate 4M14 followed by 4M12 and 1B16A than in the BS and NA samples, with NA samples having the lowest reduction rate. For example in soil amended with $4 \mathrm{M} 14$ and 4M12, there was a substantial decrease in soil TPH concentration within 15 days from $30,703 \mathrm{mg} \mathrm{kg}^{-1}$ to 170 - $664 \mathrm{mg} \mathrm{kg}^{-1}$ (97.8 to 99.4\%). The rate of TPH decrease was not significantly different in the Pseudomonas (4M14 \& 4M12) inoculated samples ( $\mathrm{P}>0.05$ ), with TPH degradation of up to $99.4 \%$ occurring by day 15 . In contrast, and despite an initial rapid reduction $(0-10$ d) $T P H$ reduction in samples inoculated with 1B16A, BS and NA samples were slower, taking an extra 10-15 days (day 25-30) for the TPH concentration to be substantially reduced to $664 \mathrm{mg} \mathrm{kg}^{-1}$ (97.8\%) and $936 \mathrm{mg} \mathrm{kg}^{-1}$ (96.9\%) respectively (Figure 1). 
Their TPH reduction rate after 10 days was significantly lower compared to TPH reduction with Pseudomonas (4M14 \& 4M12).

Overall, substantial hydrocarbon removal occurred in all microcosms by the end of the experimental period (Figure 2a and Figure 2b). Hydrocarbon degradation is thought to be enhanced in slurry phase bioremediation because the elevated moisture content used results in greater solubilisation and bio-availability of contaminants and nutrients to hydrocarbon degrading bacteria $[10,16,41]$.

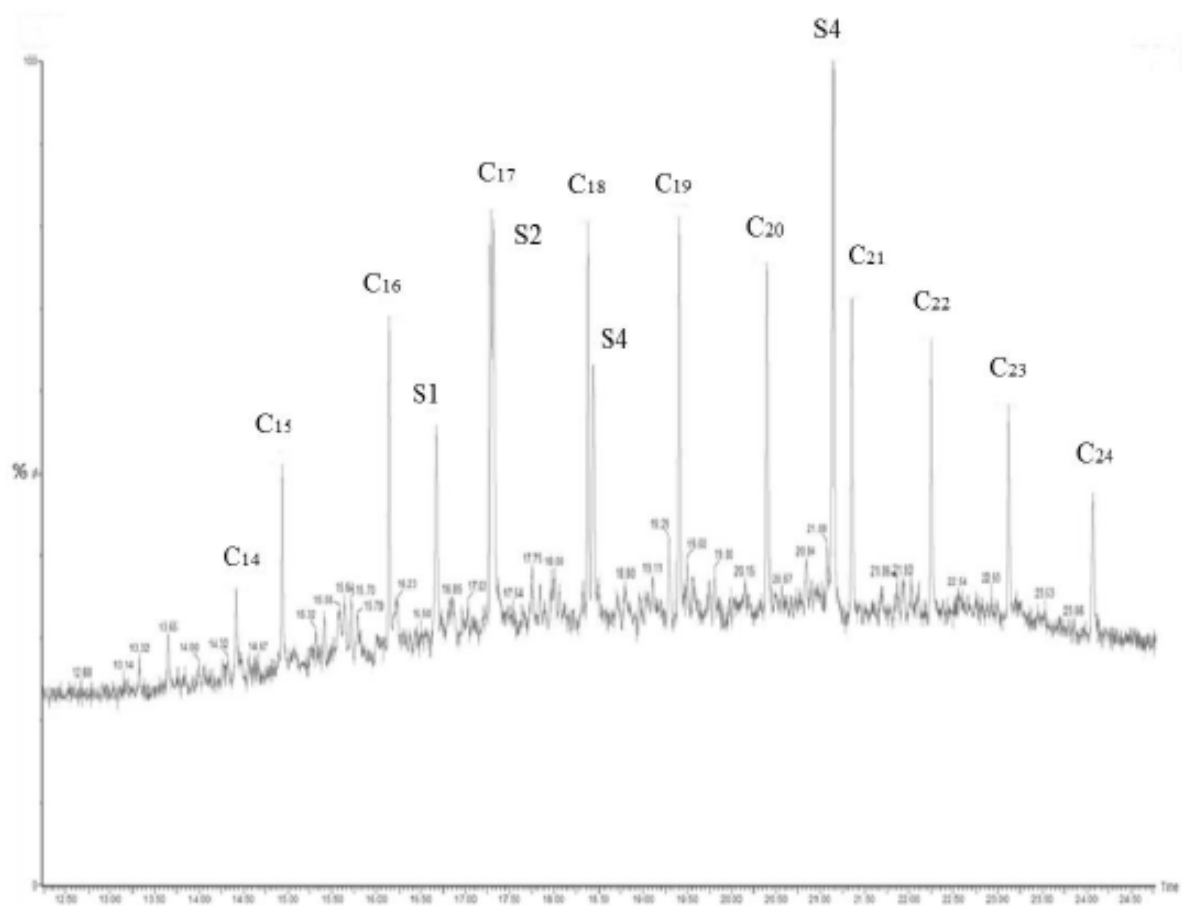

Retention time (min)

Figure 2a. Chromatogram of soil extract obtained from COTBS contaminated soil before treatment with some selected peaks identified. S1 2,6,10trimethyldodecane, S2 2,6,10,14-tetramethylpentadecane, S3 2,6,10,14-tetramethylhexadecane, S4 cyclic octa-atomic sulphur. GC-MS chromatograms of extracts from treated COTBS-contaminated soil

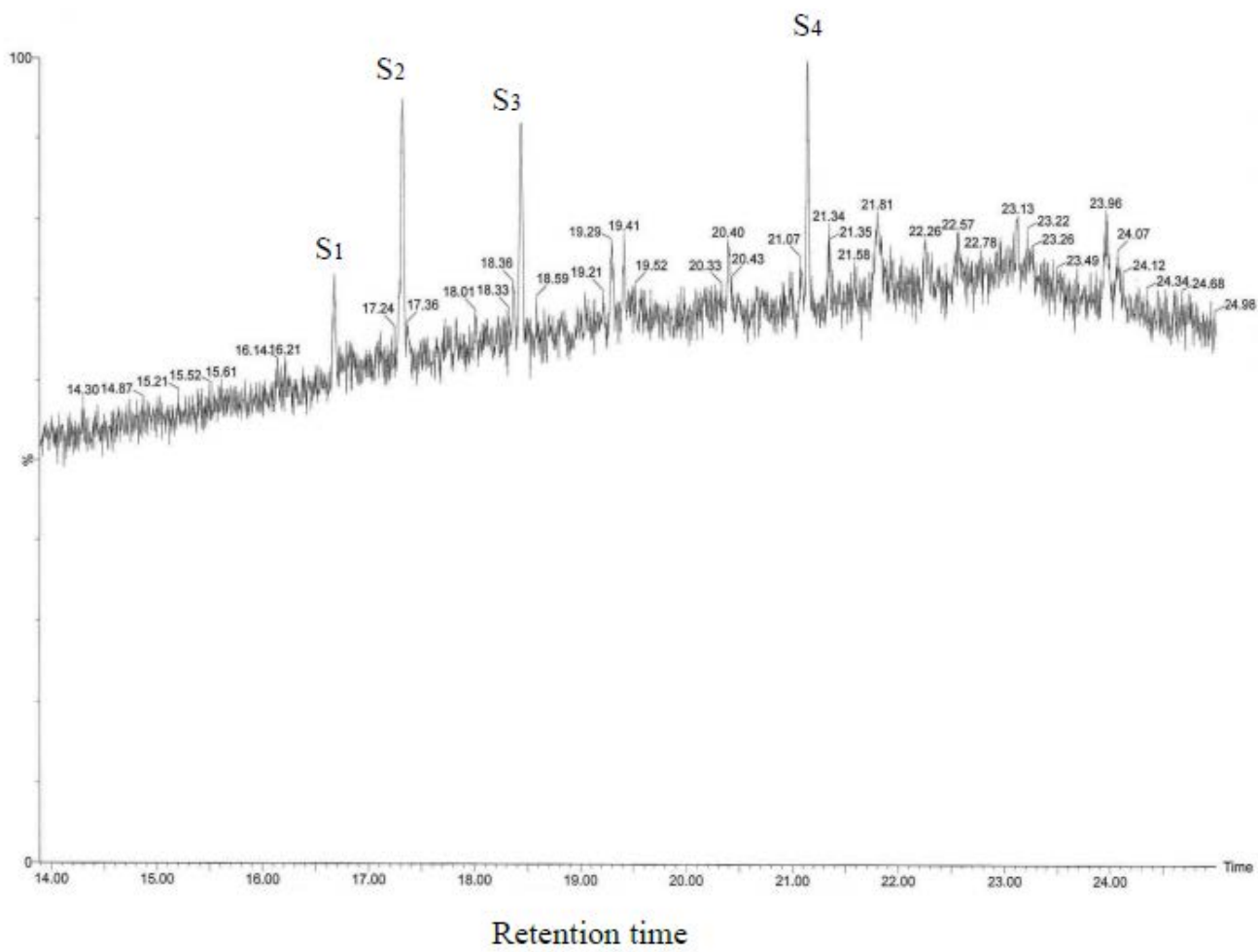

Figure 2b. Chromatogram of soil extract obtained from COTBS contaminated soil after treatment with some selected peaks identified. S1 2,6,10trimethyldodecane, S2 2,6,10,14-tetramethylpentadecane, S3 2,6,10,14-tetramethylhexadecane, S4 cyclic octa-atomic sulphur. GC-MS chromatograms of extracts from treated COTBS-contaminated soil 
TPH assay results suggest that Pseudomonas xanthomarina (4M14) and Pseudomonas sp (4M12) were the best isolates for TPH removal. The substantial reduction observed was likely due to the presence of these isolates at high concentration (via bioaugmentation) given that it took an extra 15 days for the nutrients only microcosms to reach a similar level of TPH reduction. The genus pseudomonas is known for the presence of hydrocarbonoclastic capabilities. Pseudomonads have been widely studied and isolated from different environments worldwide and are known for their capabilities of utilizing hydrocarbons as source of carbon and energy [42,43,44]. Pseudomonas sp have been successfully used to treat hydrocarbon contaminated sites. [45] studied the efficiency of Pseudomonas for the biodegradation of hydrocarbon contaminated soil in north east of India and found Pseudomonas has the ability to reduce $75 \%$ of TPH. In addition, [46] used a Pseudomonas strain in the degradation of n-alkanes in diesel oil and concluded that this strain was able to reduce $51 \%$ of the TPH.

In addition, the accelerated removal of hydrocarbon in $4 \mathrm{M} 14$ and 4M12 inoculated microcosms shows the beneficial effects of bioaugmentation-biostimulation over biostimulation alone or natural attenuation. Contaminated soil may sometimes lack a sufficient population of hydrocarbon degraders or be deficient in nutrients ( $\mathrm{N}$ and $\mathrm{P})$. Inoculating the hydrocarbon contaminated soil with indigenous hydrocarbon degrading isolates (BA) and providing the required nutrients (BS) can lead to substantial TPH reduction in contaminated soil. [47] reported that the adapted indigenous microbial isolates was responsible for better reduction of TPH $(41.3 \%$ increase) and therefore increased biodegradation efficiency. According to [48], applying BS-BA together generally increases the degradation rate of the TPH by 63$84 \%$ compared to NA).

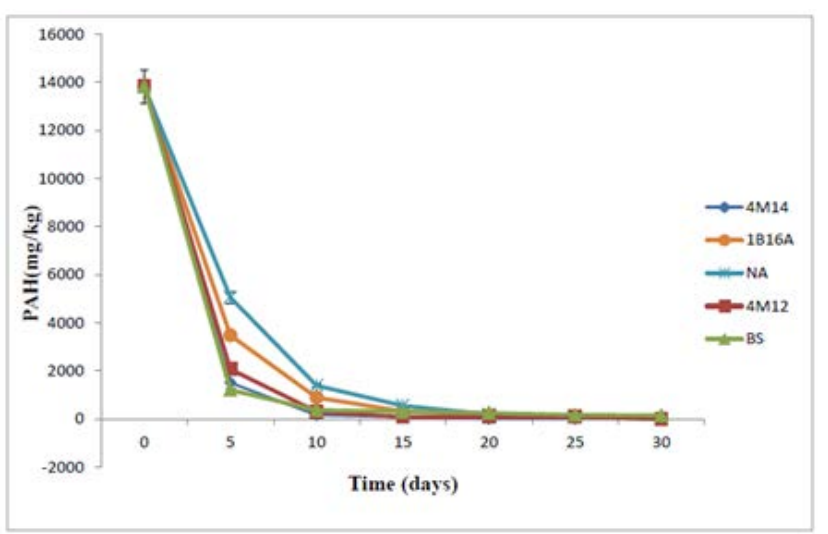

Figure 3. Reduction of PAH concentration by 3 individual bacterial isolates and NA and BS over 30 d. Diamond (4M14), circle (1B16A), asterisk (NA), box (4M12) and triangle (BS)

Note: The values of the standard errors are very low. Therefore the error bars are short and some of them are invisible.

Figure 3 shows the degradation of $\mathrm{PAH}$ in different slurry phase microcosms inoculated with Pseudomonas xanthomarina (4M14), Pseudomonas sp (4M12), Arthrobacter nitroguajacolicus (IB16A) and nutrients (BS/BA), nutrients only (BS) and controls (without any bioaugmentation or nutrients (NA). All the microcosms inoculated with 4M14, 4M12 and nutrients only showed a substantial decrease in PAH concentration from 13,816 mg kg-1 to 0 mg kg-1 or below detection limit (98.8\% $100 \%$ ) within 5-10 days. However, the PAH concentration in the 1B16A and NA microcosms showed 100\% reduction of $\mathrm{PAH}$ only after 15 days. This indicated that these isolates and other indigenous microbial communities in the slurry were better degraders of the PAH than TPH. $\mathrm{PAH}$ degradation depends on a number of environmental conditions, type of microorganisms and nature and chemical structure of the PAH fractions being degraded. $\mathrm{PAH}$ can be biodegraded and transformed into less toxic and complex fractions by mineralization into inorganic minerals and generating $\mathrm{H}_{2} \mathrm{O}, \mathrm{CO}_{2}$ in aerobic conditions or generating $\mathrm{CH}_{4}$ through anaerobic conditions [49].

Compared to other bacterial degraders, Pseudomonas is unique in its ability to metabolize hydrocarbons (single fractions and mixtures) rapidly and efficiently even at high hydrocarbon concentrations [50,51]. Pseudomonas was tested for its ability of growth on a different of hydrocarbons including various PAHs, n-alkanes and complex hydrocarbon mixture. [52] reported that the Pseudomonas $s p$ was able to remove $72 \%$ of $\mathrm{PAH}$ from $\mathrm{PAH}$ contaminated soil. [53] isolated different $\mathrm{PAH}$ bacterial degraders from sediments of the polluted Amlakadi canal, Gujarat, India and found that amongst the isolates, Pseudomonas sp showed the highest potential for $\mathrm{PAH}$ degradation being able to degrade 2000 ppm PAH within $24 \mathrm{~h}$.

\subsection{Degradation of Carcinogenic and Mutagenic Compounds}

Given that the focus of this study on the removal of mutagenic and carcinogenic fractions of COTBS contaminated samples, the extent of removal of selected mutagenic and carcinogenic fractions was examined and qualified with D50 (Removal of target fraction by 50\%) and D100 (Complete removal of target fraction). Microcosms inoculated with Pseudomonas xanthomarina (4M14) were most efficient at the complete degradation (D100) of pyrene (9 days), phenanthrene (10 days), naphthalene (9 days) and benzenamine,4,4 methylenbis[2methyl-] (10 days). Even though microcosms inoculated with 4M12 were equally effective at TPH and $\mathrm{PAH}$ removal as those inoculated with $4 \mathrm{M} 14$, their rate of removing carcinogenic and mutagenic fractions was slower. For example, an additional 5 days were needed for complete removal (D100) of pyrene (day 14), additional 3 days for $100 \%$ phenanthrene degradation (day 13), additional 2 (day 11) and 5 (day 15) days for naphthalene and benzenamine, 4,4 methylenbis[2-methyl-] removal respectively. Microcosms inoculated with Arthrobacter nitroguajacolicus (1B16A) were the slowest in removal of the 4 carcinogenic and mutagenic fractions taking between 15 to 23 days for complete removal. Overall, complete degradation of selected mutagenic and carcinogenic fractions was accomplished between 9-10 days in 4M12 and 9-15 days 4M14 while it took approximately twice this time-frame (18-22 days) to achieve the complete removal of these compounds in BS microcosms and (1823 days) in NA (Table 4).

It is important to note that although soil amended with the three selected isolates were able to completely degrade the hydrocarbon contaminants, they did so at different rates. For example, 4M12 and 4M14 had similar and 
better TPH removal profile than 1B16A, BS and NA samples. This ordinarily would have meant the selection of either of the candidates for use in a bioaugmentationbiostimulation bioremediation strategy. However, consideration of the type of carcinogenic and mutagenic fractions removed and time of removal showed that 4M14 was a better (faster) removal of these toxic fractions than 4M12. This demonstrates the benefit of carrying out these kinds of assays to assess both the time and type of removal toxic hydrocarbon fractions in isolates selected for potential use as bioaugmentation agents prior to the initiation of bioremediation.

Table 4. Biodegradation percentage of selected carcinogenic and mutagenic hydrocarbon fractions presented in soil contaminated with COTBS at D50 and D100 by bacterial isolates

\begin{tabular}{|c|c|c|c|c|c|c|c|c|}
\hline Strategies & \multicolumn{2}{|c|}{ Pyrene*b } & \multicolumn{2}{|c|}{ phenanthrene*b } & \multicolumn{2}{|c|}{ Naphthalene ${ }^{* a}$} & \multicolumn{2}{|c|}{ Benzenamine,4,4` methylenbis[2- methyl- $]^{*^{\mathrm{a}}}$} \\
\hline & D50 & D100 & D50 & D100 & D50 & D 100 & D50 & D 100 \\
\hline Microcosm+ 4M12 & 8 & 14 & 9 & 13 & 8 & 11 & 10 & 15 \\
\hline Microcosm + 4M14 & 5 & 9 & 6 & 10 & 6 & 9 & 5 & 10 \\
\hline Microcosm + 1B16A & 10 & 16 & 9 & 15 & 12 & 23 & 11 & 18 \\
\hline NA & 11 & 21 & 13 & 18 & 15 & 23 & 14 & 22 \\
\hline BS & 10 & 20 & 12 & 18 & 13 & 22 & 13 & 21 \\
\hline
\end{tabular}

\subsection{Bacterial Community Profile}

Culture independent DGGE based bacterial community profiling was used to assess changes in the different microcosms during the experimental period in order to evaluate the effect of bioaugmentation-biostimulation strategy on the natural microbial community. Figure 4a showed that there was no difference in the bacterial communities in inoculated and control microcosms at any time point. Figure $4 \mathrm{~b}$ showed the bioaugmentation agents compared to the community profile. Two of the bacterial isolates (4M12 and 4M14) had melting domains that were similar to the melting domains of some bands found on the community profile. Given that these isolates were originally from the same COTBS contaminated samples used for this assay, it is possible that the sequences of these community profile bands would be highly similar to those of the bioaugmentation bacteria. However, this will have to be confirmed by band excision, cloning and sequence analyses (which was not the focus of this study and consequently not carried out). The non-detection of $1 \mathrm{~B} 16 \mathrm{~A}$ is unusual but it might be that this isolate was not in the dominant groups that were observable through DGGE (DGGE only shows the top $1-2 \%$ population) despite its obvious importance in hydrocarbon degradation. Overall, there was no detectable change or shift in bacterial community from day 0 to day 30 with the UPGMA dendrogram showing up to $100 \%$ similarity between day 0 and day 30 and between amended and control (unamended) microcosms. This showed that despite the complete degradation of the carcinogenic and mutagenic fractions, application of hydrocarbonoclastic isolates in a nutrient solution did not change the natural community. This is important because it shows that complete detoxification of COTBS contaminated soils can be achieved without any adverse effect on the natural microbial community. This is also important for sustainable bioremediation; a concept that involves achieving detoxification targets with minimal impact on the natural community while providing long-term protection of human health and the environment (Ellis and Hadley, 2009). The accelerated removal of carcinogens and mutagens (which will result in the protection of health of personnel involved in bioremediation operations) using indigenous microbial resources without any harmful effect on the community as observed in this study suggests that the utilized biostimulation-bioaugmentation is a sustainable approach.

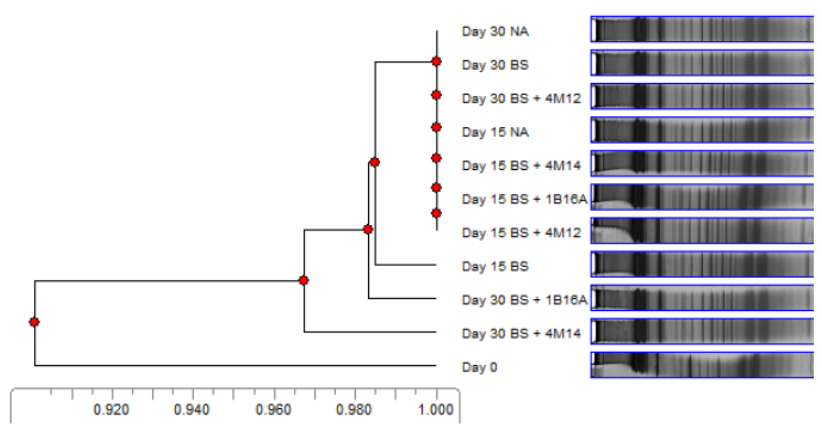

Figure 4a. DGGE profile of bacterial community in microbial and nutrient amended, nutrient only and naturally attenuated microcosms incubated for 30 days

Note: NA-Natural attenuation microcosms, BS- Biostimulation microcosms and BS+4M12, BS+4M14 and BS+1B16A are biostimulated-bioaugmented microcosms.

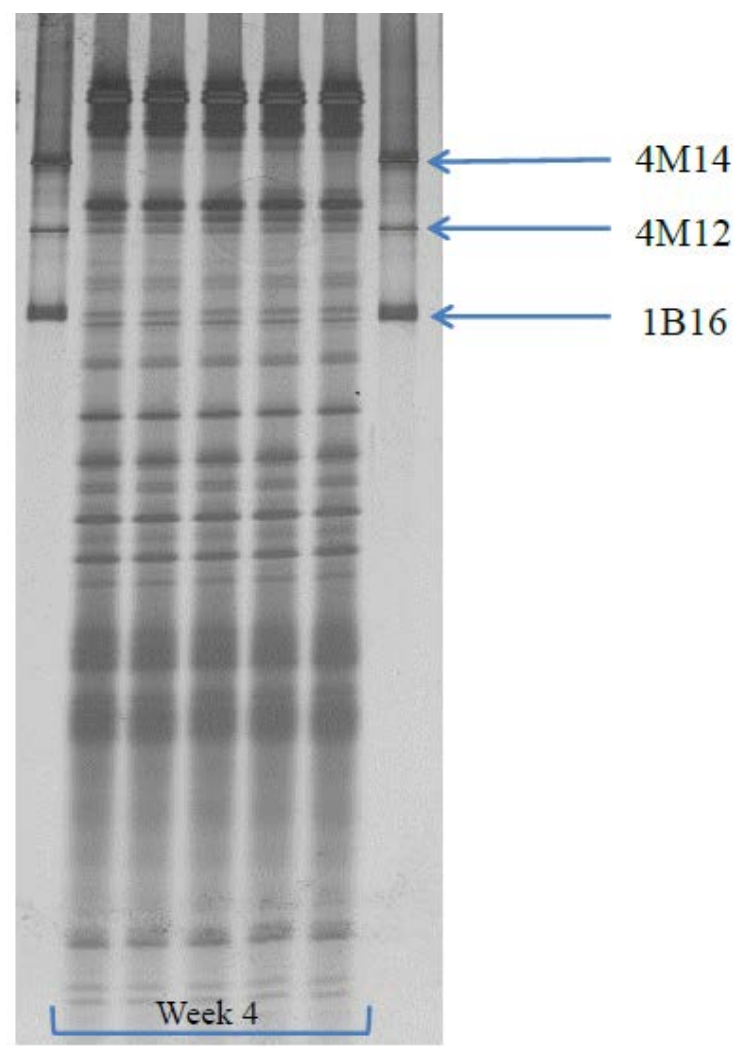

Figure $4 \mathbf{b}$. Representative community profile at week 4 showing melting domains similar to the bioaugmentation agents. First and last lanes were loaded with mixture of the three agents. The 5 profile lanes are BS+4M12, BS+4M14, BS+1B16A, BS only and NA 


\section{Conclusion}

Selection of agents for use in bioaugmentation studies is based on their endpoint TPH or PAH values in degradation studies with the removal of carcinogens and mutagens (type and time of removal) being overlooked. However, carcinogens and mutagens pose the greatest risk to human and environmental health and the earlier removal of these compounds would be beneficial to the bioremediation process. This study has demonstrated the benefit of additionally screening bioaugmentation agents for carcinogen and mutagen removal, in order to carry out safe, efficient and sustainable bioremediation. Comparing three hydrocarbonoclastic bacteria, Pseudomonas xanthomarina (4M14) was shown to be the most effective candidate for carcinogens and mutagens removal in a sustainable manner ( twice as fast compared to NA and BS samples) with minimal effects on the natural community. The application of this isolate in BS/BA approach resulted in timely and efficient removal of these hydrocarbon fractions and also demonstrates the benefit of using isolates from COTBS for treating COTBS contaminated Libyan soils.

\section{Acknowledgments}

This work was supported by the Libyan Ministry of Higher Education and Scientific research. I would like to thank the Environmental and Natural Resources Engineering, Azawia University, Libya. Also the management of Azzawiya oil refinery, Libya and my brother Ali Mansour for supplying me with soil, COTBS and petroleum crude oil samples.

\section{Reference}

[1] Mushalik, M., World Crude Production 2013 Without Shale Oil Is Back To 2005 Levels. 2014.

[2] Liu, J., et al., Pyrolysis treatment of oil sludge and model-free kinetics analysis. Journal of hazardous materials, 2009. 161 (2): p. 1208-1215.

[3] Joseph, P. and A. Joseph, Microbial enhanced separation of oil from a petroleum refinery sludge. Journal of hazardous materials, 2009. 161(1): p. 522-525.

[4] da Silva Lima, T.M., Oil recovery from fuel oil storage tank sludge using biosurfactants. Journal of Bioremediation and Biodegradation, 2011. 21

[5] Fukuhara, Y., et al., Distribution of Hydrocarbon-Degrading Bacteria in the Soil Environment and Their Contribution to Bioremediation. Applied biochemistry and biotechnology, 2013. 170 (2): p. 329-339.

[6] Boukadi, A., R. Philp, and N. Thanh, Characterization of paraffinic deposits in crude oil storage tanks using high temperature gas chromatography. Applied geochemistry, 2005. 20 (10): p. 1974-1983.

[7] Vidal, C.B., et al., Adsorption of polycyclic aromatic hydrocarbons from aqueous solutions by modified periodic mesoporous organosilica. Journal of colloid and interface science, 2011. 357 (2): p. 466-473.

[8] Crisafully, R., et al., Removal of some polycyclic aromatic hydrocarbons from petrochemical wastewater using low-cost adsorbents of natural origin. Bioresource technology, 2008. 99(10): p. 4515-4519.

[9] Koolivand, A., et al., Biodegradation of petroleum hydrocarbons of bottom sludge from crude oil storage tanks by in-vessel composting. Toxicological \& Environmental Chemistry, 2013. 95 (1): p. 101-109.
[10] Jasmine, J. and S. Mukherji, Evaluation of Bioaugmentation and Biostimulation Effects on the Treatment of Refinery Oily Sludge using 2n Full Factorial Design. Environmental Science: Processes \& Impacts, 2014.

[11] Saikia, R.R. and S. Deka, Removal of hydrocarbon from refinery tank bottom sludge employing microbial culture. Environmental Science and Pollution Research, 2013. 20 (12): p. 9026-9033.

[12] Adetutu, E., et al., Exploiting the intrinsic hydrocarbon-degrading microbial capacities in oil tank bottom sludge and waste soil for sludge bioremediation. International Journal of Environmental Science and Technology, 2014: p. 1-10.

[13] Perelo, L.W., Review: in situ and bioremediation of organic pollutants in aquatic sediments. Journal of hazardous materials, 2010. 177 (1): p. 81-89.

[14] Aislabie, J.M., et al., Dominant bacteria in soils of Marble point and Wright valley, Victoria land, Antarctica. Soil Biology and Biochemistry, 2006. 38 (10): p. 3041-3056.

[15] Woo, S.H. and J.M. Park, Evaluation of drum bioreactor performance used for decontamination of soil polluted with polycyclic aromatic hydrocarbons. Journal of Chemical Technology and Biotechnology, 1999. 74 (10): p. 937-944.

[16] Ferrari, M., et al., Biotreatment of hydrocarbons from petroleum tank bottom sludges in soil slurries. Biotechnology letters, 1996. 18 (11): p. 1241-1246.

[17] Ibarrolaza, A., et al., Application of the knowledge - based approach to strain selection for a bioaugmentation process of phenanthrene and Cr (VI) contaminated soil. Journal of applied microbiology, 2011. 111 (1): p. 26-35.

[18] Dash, H.R., et al., Marine bacteria: potential candidates for enhanced bioremediation. Applied microbiology and biotechnology, 2013. 97 (2): p. 561-571.

[19] Mrozik, A. and Z. Piotrowska-Seget, Bioaugmentation as a strategy for cleaning up of soils contaminated with aromatic compounds. Microbiological Research, 2010. 165 (5): p. 363-375.

[20] 20. Tyagi, M., M.M.R. Da Fonseca, and C.C.C.R. De Carvalho, Bioaugmentation and biostimulation strategies to improve the effectiveness of bioremediation processes. Biodegradation, 2011. 22 (2): p. 231-241.

[21] Xu, Y. and M. Lu, Bioremediation of crude oil-contaminated soil: Comparison of different biostimulation and bioaugmentation treatments. Journal of hazardous materials, 2010. 183 (1): p. 395401.

[22] Bury, S.J. and C.A. Miller, Effect of micellar solubilization on biodegradation rates of hydrocarbons. Environmental science \& technology, 1993. 27 (1): p. 104-110.

[23] Cerqueira, V.S., et al., Biodegradation potential of oily sludge by pure and mixed bacterial cultures. Bioresource technology, 2011. 102 (23): p. 11003-11010.

[24] Mansur, A., et al., Assessing the hydrocarbon degrading potential of indigenous bacteria isolated from crude oil tank bottom sludge and hydrocarbon-contaminated soil of Azzawiya oil refinery, Libya. Environmental science and pollution research international, 2014.

[25] Rowell, D.L., Soil science: methods and applications. 1994: Longman Group Limited, Longman Scientific \& Technical.

[26] Rayment, G. and F.R. Higginson, Australian laboratory handbook of soil and water chemical methods. 1992: Inkata Press Pty Ltd.

[27] Pichler, B., Biochars and their impact on nutrient retention and water mass balance in a Swiss vineyard soil, in Department of Geography. 2010, University of Zurich: Zurich.

[28] 28. Ferreira, S.L., et al., An on-line continuous flow system for copper enrichment and determination by flame atomic absorption spectroscopy. Analytica chimica acta, 2000. 403 (1): p. 259-264.

[29] Aburto-Medina, A., et al., Comparison of indigenous and exogenous microbial populations during slurry phase biodegradation of long-term hydrocarbon-contaminated soil. Biodegradation, 2012. 23 (6): p. 813-822.

[30] Machín-Ramírez, C., et al., Slurry-phase biodegradation of weathered oily sludge waste. Chemosphere, 2008. 70 (4): p. 737 744.

[31] Sabaté, J., M. Vinas, and A. Solanas, Laboratory-scale bioremediation experiments on hydrocarbon-contaminated soils. International Biodeterioration \& Biodegradation, 2004. 54 (1): p. 19-25.

[32] Oleszczuk, P. and S. Baran, Application of solid-phase extraction to determination of polycyclic aromatic hydrocarbons in sewage sludge extracts. Journal of hazardous materials, 2004. 113(1): p. 237-245. 
[33] Tang, J., et al., Characterisation of the rhizoremediation of petroleum-contaminated soil: effect of different influencing factors. Biogeosciences, 2010. 7 (12): p. 3961-3969.

[34] Jonker, M.T. and A.A. Koelmans, Extraction of polycyclic aromatic hydrocarbons from soot and sediment: Solvent evaluation and implications for sorption mechanism. Environmental science \& technology, 2002. 36 (19): p. 4107-4113.

[35] Adetutu, E.M., et al., Bacterial community survey of sediments at Naracoorte Caves, Australia. International Journal of Speleology, 2012. 41 (2): p. 2.

[36] Muyzer, G., E.C. De Waal, and A.G. Uitterlinden, Profiling of complex microbial populations by denaturing gradient gel electrophoresis analysis of polymerase chain reaction-amplified genes coding for 16S rRNA. Applied and Environmental Microbiology, 1993. 59(3): p. 695-700. 23

[37] Osborn, A.M., E.R. Moore, and K.N. Timmis, An evaluation of termina - restriction fragment length polymorphism ( $T$ - RFLP) analysis for the study of microbial community structure and dynamics. Environmental microbiology, 2000. 2 (1): p. 39-50.

[38] Girvan, M.S., et al., Soil type is the primary determinant of the composition of the total and active bacterial communities in arable soils. Applied and Environmental Microbiology, 2003. 69 (3): p. 1800-1809.

[39] Patil, S.S., M.S. Kumar, and A.S. Ball, Microbial community dynamics in anaerobic bioreactors and algal tanks treating piggery wastewater. Applied microbiology and biotechnology, 2010. 87 (1): p. 353-363.

[40] Aprill, W., et al., Assessing detoxification and degradation of wood preserving and petroleum wastes in contaminated soil. Waste management \& research, 1990. 8 (1): p. 45-65.

[41] Robles-González, I.V., F. Fava, and H.M. Poggi-Varaldo, A review on slurry bioreactors for bioremediation of soils and sediments. Microb Cell Fact, 2008. 7 (5).

[42] Das, N. and P. Chandran, Microbial degradation of petroleum hydrocarbon contaminants: an overview. Biotechnology research international, 2010. 2011.
[43] Wang, X.-B., et al., Degradation of petroleum hydrocarbons (C6C40) and crude oil by a novel Dietzia strain. Bioresource technology, 2011. 102 (17): p. 7755-7761.

[44] Zhang, X., et al., Isolation and identification of biosurfactant producing and crude oil degrading Pseudomonas aeruginosa strains. Chemical Engineering Journal, 2012. 209: p. 138-146.

[45] Das, K. and A.K. Mukherjee, Crude petroleum-oil biodegradation efficiency of Bacillus subtilis and Pseudomonas aeruginosa strains isolated from a petroleum-oil contaminated soil from North-East India. Bioresource technology, 2007. 98 (7): p. 1339-1345.

[46] Ueno, A., et al., Verification of degradation of n-alkanes in diesel oil by Pseudomonas aeruginosa strain WatG in soil microcosms. Current microbiology, 2006. 52 (3): p. 182-185.

[47] Trindade, P., et al., Bioremediation of a weathered and a recently oil-contaminated soils from Brazil: a comparison study. Chemosphere, 2005. 58 (4): p. 515-522.

[48] Bento, F.M., et al., Comparative bioremediation of soils contaminated with diesel oil by natural attenuation, biostimulation and bioaugmentation. Bioresource technology, 2005. 96 (9): p. 1049-1055.

[49] Haritash, A. and C. Kaushik, Biodegradation aspects of polycyclic aromatic hydrocarbons (PAHs): a review. Journal of hazardous materials, 2009. 169 (1): p. 1-15.

[50] Prabhu, Y. and P. Phale, Biodegradation of phenanthrene by Pseudomonas sp. strain PP2: novel metabolic pathway, role of biosurfactant and cell surface hydrophobicity in hydrocarbon assimilation. Applied microbiology and biotechnology, 2003. 61 (4): p. 342-351.

[51] Kim, S.-J., et al., Genomic analysis of polycyclic aromatic hydrocarbon degradation in Mycobacterium vanbaalenii PYR-1. Biodegradation, 2008. 19 (6): p. 859-881.

[52] Santos, E.C., et al., Anthracene biodegradation and surface activity by an iron-stimulated Pseudomonas sp. Bioresource technology, 2008. 99 (7): p. 2644-2649.

[53] Pathak, H., et al., Naphthalene degradation by Pseudomonas sp. HOB1: In vitro studies and assessment of naphthalene degradation efficiency in simulated microcosms. Journal of hazardous materials, 2009. 166 (2): p. 1466-1473. 